JOSEF BAYER

\title{
ON THE ORIGIN OF SENTENTIAL ARGUMENTS IN GERMAN AND BENGALI
}

\begin{abstract}
This paper discusses some of the consequences of Baker's (1988) Uniformity of Theta Assignment Hypothesis (UTAH) for the analysis of German and Bengali, two SOVlanguages. UTAH assigns a uniform D-structure to all the VP-internal arguments to the left of $\mathrm{V}$. Under conservative assumptions about extraposition, this approach leads to various well-known difficulties which have mainly been discussed in the literature on Dutch. I shall claim that UTAH can only be retained if German and Bengali have two alternative positions (presumably both A-positions) for the licensing of clausal complements, one in situ, i.e. to the left of $\mathrm{V}$, the other to the right of the verbal complex. The existence of these positions is essentially the result of the relation between the matrix verb and the inner architecture of the embedded $\mathrm{CP}$. Some of the consequences will be explored, especially concerning wh-movement at $S$-structure and at LF.
\end{abstract}

\section{INTRODUCTION}

This article starts with the challenge of Baker's (1988) Uniformity of Theta Assignment Hypothesis (UTAH), and some of the influences it has on syntactic analysis. The languages (German and Bengali) from which most of the data on sentential complementation under consideration are taken are SOV-languages. UTAH assigns a uniform D-structure for all of their VPinternal arguments to the left of $V$. Under conservative assumptions about extraposition, this approach leads to well-known difficulties which have been discussed mainly in the literature on Dutch. My claim is that we can retain UTAH only when German and Bengali have two alternative positions (presumably both A-positions) for the licensing of clausal complements, one in situ i.e. to the left of $\mathrm{V}$, the other to the right of the verbal complex. I will show that the existence of these positions is essentially the result of the relation that the verb has with the CP's inner architecture. Some of the consequences of this analysis will be explored, especially questions of WH-movement at S-structure and at LF.

\section{THE UNIFORMITY OF THETA ASSIGNMENT HYPOTHESIS}

In a rigidly constrained framework for phrase structure such as modern $\mathrm{X}^{\prime}$-theory it seems desirable that there is a uniform licensing relation between a head X and its complement YP. Assuming head-finality, one would expect lexical projection to work in such a way that every satisfaction of the head-complement relation would result in [[YP]X], and that [X[YP]] must arise from move- $\alpha$. This is in fact the gist of the UTAH as suggested in Baker (1988: 46). I choose (1) as a slight reformulation: 
(1) The Uniformity of Theta Assignment Hypothesis: If two maximal phrases YP and ZP' receive the same theta-role from a head X, then $\left[x^{\prime} X\right.$ YP] and $\left[x^{\prime} X\right.$ ZP] have the same D-structure

The assumption here is that D-structure is a pure level of thematic structure which is almost totally derivative from lexical information, one possible difference being the syntactic presence of an external argument. The assumption that every major category has a subject (cf. Stowell 1983) together with the VP-internal subject hypothesis (cf. Sportiche 1988, and many others) yields D-structures of the following kind: [XP specifier [ $X^{\prime} X$ [complement]]], order irrelevant. We will next discuss which predictions this makes for German sentential complementation.

\section{GERMAN CP-EXTRAPOSITIONS}

German is in important respects a head-final language, although it has frequently been classified as an SVO-language, due to the fact that it shows the verb-second property in main clauses, has mainly head-initial PPs, complements and relative clauses to the right of $\mathrm{N}$, etc. ${ }^{1}$ The examples in $(2 a, b)$ exist side by side without a noticeable difference in markedness. Clearly, the complement is theta-marked in the same way by aufhören in both cases. According to (1), (2b) must be the result of extraposition, which roughly yields the S-structure in (2c).

(2) a. Hans hat [PRO zu rauchen] aufgehört Hans has to smoke stopped

'Hans has stopped smoking'

b. Hans hat aufgehört [PRO zu rauchen]

c. Hans hat $e_{i}$ aufgehört [PRO zu rauchen $]_{i}$

Given this, it could be expected that German allows movement from a CP-complement only as long as it is in its c(anonically)-governed position to the left of the verb, as in (3a). In fact however, WH-movement largely looks like in English i.e. it can proceed from the extraposed CP as in (3b).

(3) a. Welches Haschisch ${ }_{i}$ hat Hans [PRO $e_{i}$ zu rauchen] aufgehört?

b. Welches Haschisch ${ }_{\mathrm{i}}$ hat Hans $\mathrm{e}_{\mathrm{j}}$ aufgehört [PRO $\mathrm{e}_{\mathrm{i}}$ zu rauchen] $]_{\mathrm{j}}$ ? 'Which (kind of) pot has Hans stopped smoking?'

Since Ross (1967), it has been a commonplace in linguistics that extraposition leads to a "frozen" structure which resists extraction (Which bed did you sleep in several times? versus *Which bed did you sleep several times in?). As de Haan (1979) and Koster (1987) have remarked, such an 
effect is entirely absent in Dutch and German long WH-movement. Both authors concluded from this that clausal complements to the right of $\mathrm{V}$ must be already present in D-structure. Before we turn to this suggestion in detail, let me mention that for speakers like myself, it is in addition completely natural to extract from successively embedded $d a \beta$-complements:

(4) Wie $e_{i}$ hast du gemeint $\left[_{C P} e_{i} I_{C^{\prime}} d a \beta\left[_{I P}\right.\right.$ sie gesagt hat $I_{C P} e_{i}$ how have you thought that she said has

[ $\mathrm{C}^{\prime}$ daB [IP der Karl $e_{i}$ das Bild gemalt hat]]]]]]? that the Karl the picture painted has

'How did you think that she has said that Karl has painted the picture?"

UTAH forces us to a rather intricate extraposition analysis according to which (4) has a D-structure roughly like in (5).

(5) $\quad\left[{ }_{\mathrm{CP}}-\left[_{\mathrm{C}^{\prime}}-\mathrm{IIP}_{\mathrm{IP}} \mathrm{du}\left[\mathrm{CP}-\left[_{\mathrm{C}^{\prime}}\right.\right.\right.\right.$ daß $\left[_{\mathrm{IP}}\right.$ sie $\left[_{\mathrm{CP}}-\left[_{\mathrm{C}^{\prime}} \mathrm{da}\right.\right.$ $[$ IP der Karl wie das Bild gemalt hat]]] gesagt hat]]] gemeint hast]]]

Several steps are needed in order to arrive at the S-structure shown in (4): First, WH-movement will take wie from its D-structure position through the lowest Spec-CP into the medial Spec-CP. In order not to come into conflict with the cyclic principle, the CP daß der Karl das Bild gemalt hat now has to be extraposed to the right of the current (medial) CP. This results in the string du wie daß sie gesagt hat daß der Karl das Bild gemalt hat gemeint hast. Then the finite verb hast has to move to the empty C-position of the matrix in order to create a V2 structure which licenses the ultimate landing site of the WH-operator. After the WH-element has moved to the highest Spec-CP, the string daß sie gesagt hat daß der Karl das Bild gemalt hat will be extraposed to the right of the matrix clause. Though at first sight technically elegant, this analysis creates empirical as well as conceptual problems. The first problem is quite straightforward, and has already been mentioned: If core grammar move- $\alpha$ (here WH-movement) can be followed by extraposition shifting the "remnant" to the right of VP or IP, why should this analysis be impossible in all those cases in which the freezing effect is observed? One could say that extraposition of CPs is forced by Kayne's (1982) or Hoekstra's (1984) Unlike Category Condition (UCC), but this leads to obvious problems with data such as (2a). ${ }^{2}$ If the head of the infinitival clause induces any features, they will include $[+V]$, because $V$ raises to the I-element $z u$. (See also my discussion of $z u$-infinitives in section $3)$.

Second, an analysis of cyclic WH-movement with subsequent extraposition of the CP (the source of movement) to a righthand $A^{\prime}$-position 
involves $A^{\prime}$-traces inside $A^{\prime}$-traces. The computation of the operator/variable relation in (4) will not be able to follow the steps indicated in the representation above but rather presupposes the computation of two other traces (of the same kind?) in which the variable is buried:

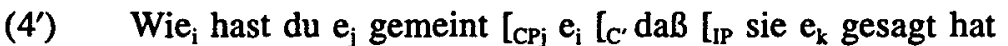
$\left[{ }_{C P k} e_{i}\left[C^{\prime}\right.\right.$ daß [IP der Karl $e_{i}$ das Bild gemalt hat]] ]]]]?

This is an example of layered traces. Fanselow (1993) and Müller (1993: ch. 7) show that traces of the same type cannot be layered. ${ }^{3}$ If they are right, the extraposition trace (if any) should be significantly different from the WH-trace. From the viewpoint of syntactic processing, the S-structure in $\left(4^{\prime}\right)$ is also strange. The $A^{\prime}$-chain headed by wie has to be computed after the extraposed $\mathrm{CP}$ is reconstructed into its $\mathrm{D}$-structure position. Otherwise the structure would have to be rejected as an island violation. Undoing extraposition in the sense of active gap filling is a complication that would slow down the on-line computation of the WH-chain. This creates at least a conceptual problem because it has been known since Miller and Chomsky (1963), Kimball (1973) and others that if extraposition affects parsing in any sense, it will reduce and certainly not increase parsing complexity. Thus, if extraposition still takes place in the way described above, its traces must be rather irrelevant for the processor. Under the assumption that the competence grammar is responsible for the representations which the processing device will make use of, the traditional extraposition analysis has nothing to recommend.

Consider third a case in which there can be no doubt that the CPcomplement is in an $\mathrm{A}^{\prime}$-position. What $\mathrm{I}$ have in mind are cases in which a pronominal (in German es) appears in c-governed position. (See Bennis 1986: ch. 2 for discussion mainly with respect to het in Dutch). In German, as in any other language I am aware of, extraction from a CP linked to a theta-marked dummy like es always leads to serious ungrammaticality as shown in (6b).

(6) a. Hans hat $\left(\mathrm{es}_{\mathrm{i}}\right)$ geglaubt $[\mathrm{da} \beta \text { sein Chef uns verachtet }]_{i}$ Hans has (it) believed that his boss us despises

b. Wen ${ }_{j}$ hat $\left({ }^{*} e s_{i}\right)$ Hans geglaubt $\left[\mathrm{da} \beta\right.$ sein Chef $e_{j}$ who has (it) Hans believed that his boss

verachtet $]_{i}$ ?

despises

In connection with es, one also finds the well-known restriction against complementizerless tensed CPs

(7) The boy knew it *(that) his dad would come 
(8) Der Junge wußte es...
a. daß sein Vater kommen wird
( $C$ and $V$-end)
b.* sein Vater wird kommen
(no $C$ and $V 2$ )

Once there is an overt pleonastic element, the coindexed CP in $\mathrm{A}^{\prime}$-position has to be supported by a lexical complementizer. Stowell (1981: ch. 6) gives an explanation in terms of the ECP: The head of a CP can only be missing if the CP - and by virtue of this, its head - is properly governed. In (7), it occupies the position which is properly governed, thus the $\mathrm{CP}$ must be in an $A^{\prime}$-position where an empty head could not be licensed. Of course, Stowell's explanation does not directly carry over to cases like (8) because in German V2 clauses the C-position is filled by the finite verb. ${ }^{4}$ Relevant for us is the fact that in the absence of es, V2 clauses are perfectly grammatical in the position to the right of a (non-factive) matrix verb, while their distribution otherwise closely resembles that of English CPs with a zero complementizer. For instance, V2-clauses in situ are completely impossible. The UCC could attribute this to the fact that they carry a $[+V]$ feature. Given that infinitivals (and, as we shall see, certain Bengali tensed sentences with the feature $[+\mathrm{V}])$ are grammatical in this context, it is unlikely that the UCC is the right principle for excluding V2-clauses from this context. ${ }^{5}$

To sum up, we have found on the basis of German data a number of arguments which speak against CP-extraposition as a means of licensing CPs to the right of V, at least as long as we follow the standard assumption that extraposition is a movement rule that falls under trace theory and moves a phrase to an $A^{\prime}$-position. Once we bring Bengali into the picture, further complications for this theory will arise. The alternative, base generation of $\mathrm{CP}$ to the right of the verb, will of course considerably weaken UTAH. We will next consider the architecture of CP in more detail, and derive some generalizations as to their position relative to the verbal governor.

\section{HOW TO LICENSE CP}

\subsection{C-Visibility}

It has been suggested by much of the writing in generative grammar that CPs are subject to somewhat different licensing conditions from NPs (or DPs). The observation that the latter need Case while the former don't does not delimit the problem sufficiently. Let us assume that the matrix verb may head-govern a CP-argument on its non-canonical side, and that it does so under a special condition which guarantees that the category to be governed is visible for its governor under adjacency. ${ }^{6}$ Such a condition must attend to the following structures, the last of which is valid for Southern German only: 
(9) a. pure daß-complements

Hans sagte [daß er keine Zeit hätte]
Hans said that he no time had

b. V2-complements

Hans sagte [er hätte keine Zeit]

c. WH-complements

Hans fragte [warum er keine Zeit hätte]

Hans asked why he no time had

d. $W H+$ daß-complements (Bavarian)

Hans fragte [warum daß er keine Zeit hätte]

Following suggestions in Chomsky (1986) and Rizzi (1990), one can guarantee CP-visibility with the help of Spec-Head Agreement (SHA). For (9a) we can either assume that Spec-CP remains inert and has been deleted, or that a featurally unmarked empty Spec-CP adopts the features of C. In both cases it is guaranteed that the features of the CP's head are visible for the adjacent matrix verb (or V-complex). The element which determines the feature structure of the V2-complement in (9b) is the tensed verb which has moved to $\mathrm{C}$ by I-to-C movement. In this sense, V2 turns the CP (again) into an IP, the difference from the original IP being that the Spec-position to the left of $\mathrm{C} / \mathrm{I}$ is now an $\mathrm{A}^{\prime}$-position. Let us assume that $I$ in $C$ has strong features which are copied onto the XP in Spec, thus making CP visible for the matrix verb. ${ }^{7}$ Under the assumption that the WH-phrase in (9c) is in Spec-CP while the zero-C is featureless, SHA will mark $\mathrm{C}$ as $[+\mathrm{WH}]$. Since $d a \beta$ has weak features ("no conceptual semantic content"), we can assume that the same thing happens in (9d). In both cases it is guaranteed that $\mathrm{CP}$ is visible as an interrogative complement. Our suggestion above was that $\mathrm{CP}$ may arise in a post-verbal A-position. ${ }^{8}$ If this is the case, it is not totally surprising to see that extraction from such a CP is possible. At the same time there is overwhelming evidence that German follows a parameter that is set for the head-finality of its VP, and as such has a pervasive influence on the syntax of this language in comparison with Germanic VO-languages. Why is it then in most of the cases quite awkward to have a tensed CP (e.g. with a daßcomplementizer) in a c-governed A-position? It has repeatedly been observed in the literature that a $\mathrm{CP}$ of this sort must either scramble to the left or move to Spec-CP.9 Again, one could think of a solution along the lines of the UCC, but we have seen already that this cannot explain easily why $z u$-infinitives (also those with CP-status) can remain in situ. ${ }^{10}$

Another complication is that $d a \beta$-CPs can occur in this position as long as they are short enough to avoid serious effects of center embedding. Consider (10) where the CP undoubtedly has remained inside VP. 
(10) Als Hans [vp gestern [vp seiner Schwester [daß er when Hans yesterday his sister that he krank sei] sagte]] waren alle schon weg ill is said were all already away

'When Hans told his sister yesterday that he was ill, everybody had left already"

Let us assume that short CPs of this sort can - as a marked option - be captured by an NP-over-S analysis i.e. (10) would involve a substructure like [VP seiner Schwester [NP $_{\mathrm{NP}}$ [CP daß er krank sei]] sagen], and that this exempts the complement from being licensed by the verb directly. "Once this strategy fails and the CP has to be licensed as such, there is no strictly local relation between $C$ and $V$. I assume that in this case the verb will s-select a CP, but it will not license CP as a category. We can isolate three strategies for licensing a CP-complement: One by C-visibility, which is essentially an adjacency requirement by which $C$ must appear on the edge of the clause that is next to the verb at S-structure; one by NP-over-S; and one by mediating the local relationship between $\mathrm{V}$ and $\mathrm{CP}$ with a trace. In this way the effect of the UCC is captured, but now for the completely different reason that - unless NP-over-S can be invoked - nonadjacency of $\mathrm{C}$ and $\mathrm{V}$ is to be avoided. Once the $\mathrm{CP}$ is moved leftwards, there is no necessity for its head to be visible for the matrix verb because traces only accidentally transmit absolute literal categorial forms to their base position. ${ }^{12}$

Our suggestion for ruling out structures like $\left[\mathrm{VP}_{\mathrm{VP}}[\mathrm{CP} \mathrm{C} \ldots\right.$. . V] makes interesting predictions for complements not considered so far, namely $z u$-infinitives. Consider the following data. ${ }^{13}$

(11) a. Hans hat bedauert [die Tür $\mathrm{e}_{\mathrm{i}}$ ] gestrichen $\mathrm{zu}$ haben Hans has regretted the door painted to have

[die in den Hof führt] ${ }_{i}$ which into the yard leads

'Hans has regretted to have painted the door which leads into the yard"

b. [[Die Tür $\left.e_{i}\right]$ gestrichen zu haben [die in den Hof führt $\left.]_{i}\right]_{j}$ hat Hans nicht $e_{j}$ bedauert

c. weil Hans [[die Tür $e_{j}$ ] gestrichen zu haben [die in den Hof führt $]_{i}$ ] schon oft $e_{j}$ bedauert hat

d. ${ }^{*}$ weil Hans [[die Tür $\left.e_{i}\right]$ gestrichen zu haben [die in den Hof führt $]_{i}$ ] bedauert hat

e. weil Hans [[die Tür $e_{i}$ ] gestrichen zu haben] bedauert hat [die in den Hof führt $]_{i}$ 
In $(11 \mathrm{a}, \mathrm{b}, \mathrm{c})$ the relative clause die in den Hof führt can extrapose and attach to the infinitival clause. The infinitival clause itself is extraposed, topicalized, and scrambled respectively. Attachment of the relative clause to the infinitival clause is, however, strictly impossible in (11d) ${ }^{14}$ Notice that here the $z u$-infinitive is to the immediate left of the matrix verb. (11e) shows that in this case the relative clause can only attach to the main clause. Can this distribution be captured by our idea of CP-visibility? It can, if we consider the suggestion by Wilder (1988) that $z u$ is a CP-final complementizer. ${ }^{15}$ Most current analyses take $z u$ as an instantiation of tenseless I (see for example Evers 1990), while C is taken to be a CP-initial zero complementizer. While I take this to be essentially correct for infinitivals to the right of the verb, I want to suggest that infinitivals to the left of the verb may use $z u$ as the instantiation of a final complementizer. ${ }^{16}$ The diagram in (12) shows how this can be achieved by head movement: ${ }^{17}$

(12)

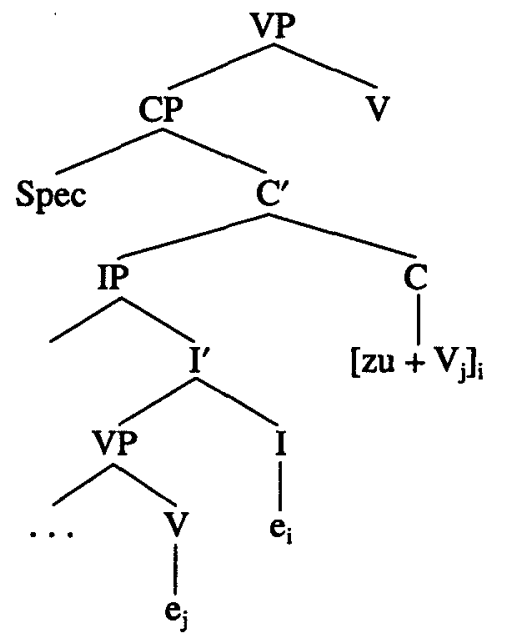

The datum in (11d) suggests that CPs need to be licensed under C-visibility not only when arising to the right of $\mathrm{V}$, but also when c-governed. In (12) the matrix $\mathrm{V}$ can recognize its complement via its $\mathrm{C}$-head. For cases such as (11d) we want to assume that adjunction disrupts this headto-head visibility. ${ }^{18}$

We are now in a position to give a definition of $\mathrm{C}$-visibility, which as we have shown above, breaks down into a number of subcases.

(13) $\mathrm{C}$ is visible for its governor $\mathrm{V}$ iff either one of (i) through (iv) holds: (i) $\mathrm{V}$ governs a trace of $\mathrm{CP}$, (ii) $\mathrm{V}$ is head-adjacent to $\mathrm{C},{ }^{19}$ (iii) due to SHA a feature appears on Spec-CP which satisfies V's s-selection requirements, (iv) the C-head has nominal features and can (under certain conditions such as brevity) optionally be treated as an NP. 
To sum up, we have isolated specific restrictions on the licensing of CPs with argument status which are clearly different from what can be observed with respect to categories such as NP and PP. The latter are entirely free of the head adjacency requirement, but are subject to other restrictions such as Case assignment. While many questions had to be left open, it seems obvious that a specific inner architecture of $\mathrm{CP}$ is necessary for it to be visible for a verbal governor.

\subsection{Extraposition as argument shift}

In my argumentation so far I have assumed that in German (or Dutch) a righthand CP-complement is in a position that is equivalent to an A-position. This leaves two options: Either it can be (optionally?) base generated there, or it moves to this position in the sense of argument shift. ${ }^{20}$ The first option is, of course, incompatible with UTAH. I try to give a more restrictive account, and will follow Hoekstra (1987), where an extraposition analysis in the sense of argument shift is proposed. Hoekstra notices that old-style extraposition to some $A^{\prime}$-position cannot account for the fact that the righthand $\mathrm{CP}$ allows extraction, and that the $\mathrm{CP}$ is likely to shift to an A-position. How can this be the case? Hoekstra first turns to the role of traces, and notices that the primary reason for their presence is the fact that the Projection Principle has to be observed on all levels of representation. If it were not for the Projection Principle, traces could just as well delete. The lexically induced relations would then have to be fully recoverable in the output of the transformation. Consider now the structure in (14):

$$
\left[r ^ { \prime } \left[I^{\prime}\left[v p e_{i} e_{j}\right]\left[\begin{array}{lll}
V_{j} & V_{j} & C_{i}
\end{array}\right]\right.\right.
$$

If $e_{i}$ gets deleted, the Projection Principle is violated because the trace of the verb $\left(e_{j}\right)$ requires an object. If $e_{j}$ can likewise be deleted, however, this problem disappears; there is neither a licenser nor a licensee. The question is then how the shifted CP will get $\theta$-marked. It is easy to see that this cannot be a problem because $\mathrm{V}$ has been adjoined to $\mathrm{I}$ and thus the newly formed head $\{\mathrm{V}+\mathrm{I}\}$ is able to govern whatever $\mathrm{V}$ had governed at $\mathrm{D}$-structure. ${ }^{21}$ Formally, the rightward shift can be characterized as adjunction to $I^{\prime}$. After deletion of the traces $e_{i}$ and $e_{j}$, the structure of (14) will look as in (15), where $I$ indicate the deletion sites with an asterisk:

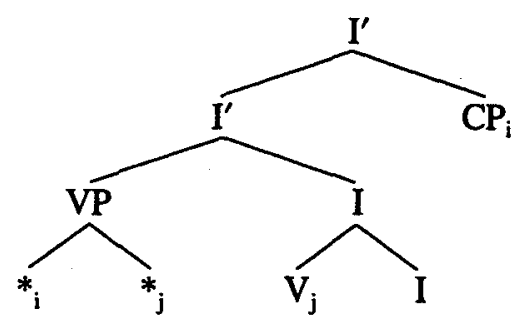


The percolation of $V_{j}$ in the complex head $I$ and its projection $I^{\prime}$ allows $\mathrm{V}_{\mathrm{j}}$ to obtain a relation to $\mathrm{CP}_{\mathrm{i}}$ that is formally equivalent to sisterhood. If we adopt the notation of Bayer and Kornfilt $(1990,1994)$, we can make this relation transparent:

(16)

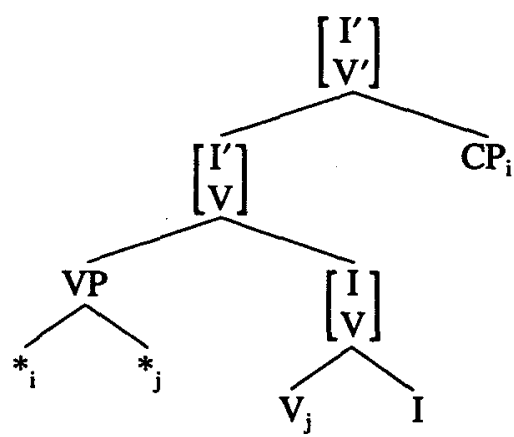

As Hoekstra points out, the presence of a nominal (or prepositional) object of $\mathrm{V}$ disallows the deletion of the $\mathrm{V}$-trace because this would leave the object without a $\theta$-role. In that case, $\mathrm{CP}$ can only be licensed as an adjunct, and as such it is correctly predicted that extraction from it will yield a CEDviolation (see Huang 1982).

Two problems could arise from this proposal: First, the VP may contain more arguments than just the $\mathrm{CP}$-argument, and the question arises how these can be $\theta$-licensed when trace deletion has occurred. Second, as Haider (1993a,b) has noticed, the extraposed CP must be c-commanded not only by the subject but also by the objects that stay to the left of $V$. This can be seen in the examples (17a) and (17b), which show a bound pronoun reading and a principle $C$ violation, respectively:

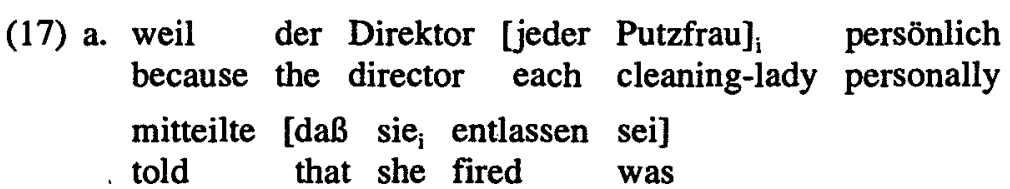

b.*weil der Direktor ihr $_{i}$ persönlich mitteilte $\left[\mathrm{da} \beta\right.$ die Putzfrau ${ }_{i}$ entlassen sei]

These two problems are obviously related, and a solution requires that everything that is licensed by the verb has to be scrambled out of the VP. This is in the spirit of Chomsky (1992), but it is not obvious in which sense the VP-external licensing of the arguments should arise. Chomsky has to assume a separate functional projection for each argument that needs to be licensed. Since there is no S-structure in his framework but only LF, one could say that the Binding Principles always apply at LF; in that case it does not matter whether the arguments have been moved overtly or movement has been procrastinated. ${ }^{22}$ Alternatively, one could argue in 
the spirit of Bayer (1990), Bayer and Kornfilt $(1990,1994)$ and Haider $(1992,1993 a, b)$ that in head-final languages like German, V and I are collapsed, and that $\mathrm{V}$ encodes all the functional elements that are necessary to license its arguments along its projection line. Pursuing these possibilities further would go far beyond the limits of this article. I will therefore stop this discussion here, and sum up what we have found so far: Given Hoekstra's (1987) proposal of CP-extraposition to a quasi A-position we can account for the fact that cyclic movement from a righthand $\mathrm{CP}$ is possible, while at the same time keeping to UTAH's requirement of a uniform D-structure basis for $\theta$-assignment. At the same time, this analysis guarantees that the clausal complement has moved to a position that deviates from the c-governed position to the left of $\mathrm{V}$. This has important consequences which again I cannot review here. ${ }^{23}$ It suggests, for instance, that CP-topicalization can only occur from a c-governed position to the left of $\mathrm{V}$, and that movement from the derived A-position's impossible. As I will argue later on, rightward shift turns the VP into a barrier (for certain processes). One can see this effect in sentences which can optionally be licensed by a pronominal adverb:

(18) a. weil er [darum [daß man ihm helfen möge]] because he there+about that one him help will

gebeten hat

asked has

'because he asked that one should help him'

b. [darum $[\mathrm{da} ß \mathrm{man}$ ihm helfen möge $]]_{i}$ hat er $e_{i}$ gebeten

(19) a. weil er gebeten hat [daß man ihm helfen möge]

b. $\mathrm{Wem}_{\mathrm{j}}$ hat er gebeten [daß man $\mathrm{e}_{\mathrm{j}}$ helfen möge]? 'Who has he asked that one should help?'

c.* $[\mathrm{da} \beta \text { man ihm helfen möge }]_{i}$ hat er gebeten $e_{i}$

Bitten subcategorizes for a PP; darum fulfils this requirement, as shown in (18), where topicalization of the PP+CP constituent is possible. (19a) shows that the PP can be missing, in which case the CP appears in the post-verbal position. This position cannot be an adjunct position because - as (19b) indicates - it permits WH-movement. If the CP itself, however, could be moved from this righthand position, we could, contrary to fact, expect (19c) to be grammatical. My conjecture is that C-visibility as defined in (13) is the driving force behind the rightward shift of clausal complements in the verb-final language German, and that the identification of a CP-complement via a trace is only possible where the trace appears in the canonical position to the left of $\mathrm{V}$.

I want to show in section 6 that the generation of an argument to the right 
of the verb is still not cost free. Before doing this, let us next have a look at the complementation system of Bengali, where some striking similarities with German can be observed.

\section{COMPLEMENTATION IN BENGALI ${ }^{24}$}

Bengali (or Bangla), one of the major eastern Indo-Aryan languages, is to a large extent head-final like Turkish or Japanese i.e. it is typologically a classic case of an SOV-language. Bengali, for instance, does not have prepositions at all; it has right-headed APs, and a kind of relative clause (gerund) to the left of the noun on which relativization occurs. One peculiarity which makes Bengali comparable to Germanic SOV-languages like German or Dutch is, however, that it allows the extraposition of finite sentential complements.

(20) a. CP in situ

$$
\begin{array}{llll}
\text { chele-Ta [or baba as -be] } & \text { Sune-che } \\
\text { boy -[cl] his father come-[fut] hear-[past] }
\end{array}
$$

'The boy has heard that his father will come'

\section{b. CP extraposed \\ chele-Ta Sune-che [or baba aS-be] \\ (same meaning)}

Since Bengali is a head-final language in most respects that are relevant for making typological distinctions, we can say that the (CP-) complement is c-governed by Sona ("to hear") in (20a), but not in (20b), where it is extraposed in the sense of argument shift as we have argued for German. I will suggest here that the situation is almost exactly like in German. In order to do this, it is important to look at cases where overt complementizers appear. One interesting fact about Bengali sentential complementation is that there are two complementizer-like words which have virtually nothing in common, neither morphologically nor categorically. One is $j e$, the other is bole. There is some controversy about both in the literature whose review would exceed the limits of this article. ${ }^{25}$ The best informal characterization of clauses headed by these two complementizer-like elements I have found is the following:

"... the bole-clauses [. . .] prefer to occur towards the western site (i.e. S-initially) of the whole sentence, whereas the $j e$-clauses would prefer to be moved towards the eastern site as the application of a rightward extraposition rule [. . .]"

Singh (1980: 190f)

bole (as well as Oriya boli) is the participial form of the verbum dicendi bol- ("say"). Similar uses of a verb of speaking as a clause-final comple- 
mentizer are attested in various Dravidian languages. ${ }^{26}$ With the bolecomplementizer present, (20a) comes out as (21).

$$
\begin{aligned}
& \text { chele-Ta [[or baba aS -be] bole] Sune-che } \\
& \text { boy -[cl] his father come-[fut] [comp] hear-[past] } \\
& \text { 'The boy has heard that his father will come' }
\end{aligned}
$$

As suggested by Singh, bole-complements like in (21) generally cannot be extraposed. ${ }^{27}$ Consider now je-clauses. The alternative to (20b) is (22).

$$
\begin{aligned}
& \text { chele-Ta Sune-che [je [or baba aS -be]] } \\
& \text { boy -[cl] hear -[past] that his father come-[fut] } \\
& \text { (same as (21)) }
\end{aligned}
$$

$\mathrm{Je}$ - and bole-clauses are in complementary distribution as it is impossible to have the je-clause in the c-governed position to the left of Sune-che. ${ }^{28}$ Thus, we get the following ungrammatical constructions.

$$
\begin{aligned}
& \text { (23) a.* chele-Ta Sune-che [lor baba aS-be] bole] } \\
& \text { b.*chele-Ta [je [or baba aS-be]] Sun-e-che }
\end{aligned}
$$

One apparent complication is that preverbal je-clauses do appear in Bengali, but there is evidence that in these cases $j e$ is not a complementizer. Consider the following example:

$$
\begin{aligned}
& \text { chele-Ta [[or baba je aS -be] Sone-ni } \\
& \text { boy -[cl] his father ? come-[fut] hear-[past,neg] } \\
& \text { 'The boy hasn't heard that his father will come' }
\end{aligned}
$$

If $j e$ were a complementizer here, this would be striking evidence against head peripherality. The C-projection would be nested in the I-projection. Furthermore, je in (24) is mobile. Inside IP it may cliticize onto any major constituent, not only the subject-NP. Dasgupta (1980) has argued that je starts out as a complementizer and gets subsequently lowered into the clause, but he has since argued (see Dasgupta 1984, 1987) in favor of distinguishing this use of $j e$ (which he calls an anchor) from its use as a complementizer (in his terms a subjoiner). The most direct evidence against the role of $j e$ as a complementizer in cases like (22) comes from Singh's (1980) observation that it may co-occur with bole. Consider (25), which slightly changes Singh's own example, and (26) which is an Oriya example from Bal (1990).

$$
\begin{aligned}
& \text { [[chele je por -be] bole] ami mon -e } \quad \text { kori ni } \\
& \text { boy ? study-[fut] [comp] I mind-[loc] do [neg,past] } \\
& \text { 'I haven't thought that the boy will study' }
\end{aligned}
$$

$$
\begin{aligned}
& \text { se [CP raama je maacha khaae boli] jaane } \\
& \text { (s)he Rama? fish eats [comp] knows } \\
& \text { '(S)he knows that Rama eats fish' }
\end{aligned}
$$


It would violate fundamental properties of $\mathrm{X}^{\prime}$-syntax if there were doubleheaded CPs. Thus, it seems quite safe to assume that the IP-internal .je is not a complementizer. ${ }^{29}$ Let us then maintain that Bengali has - perhaps under very different influences in its history - acquired two words, bole and $j e$, that can both serve as complementizer-like subordinators.

(21) through (23) strongly suggest that we are again dealing with cases of head adjacency between $\mathrm{V}$ and $\mathrm{C} .{ }^{30}$ Thus, irrespective of the overtness of the complementizer there seem to be the following two options:

(27) a. ...V [ [CP $\left.\left[C, j e / \varnothing\left[I_{P} \ldots ..\right]\right]\right]$

b. ... [ [CP $\left[C^{\prime}\left[{ }_{I P} \ldots.\right]\right.$ bOle/Ø]] V

We have indirect evidence that there is indeed a final $\mathrm{C}$-position even if bole is absent, and it is likely that the inflected verb moves into this position. To see this, notice that Bengali, despite its being a strict OV-language allows NPs and other phrases to move to the right of the verb. The semantic effect is similar to clefting. While this is possible in root clauses such as (28a) and in extraposed clauses such as (28b), it is strictly impossible when the CP remains in c-governed position. ${ }^{31}$

$\begin{array}{ll}\text { (28) a. babul } e_{i} & \text { kha-be } \text { ruTi }_{i} \\ \text { Babul eat -[fut] bread }\end{array}$

'It is bread that Babul will eat'

b. ami Sune-chilam $\left[(j e)\right.$ babul $e_{i}$ kha-be $\left.\mathrm{ruTi}_{i}\right]$ I hear-[past] that Babul eat-[fut] bread

'I have heard that it is bread that Babul will eat'

c.* ami [babul $e_{i}$ kha-be ruTi $i_{i}$ ] Sune-chilam

d. ami [babul ruTi kha-be] Sune-chilam

We have suggested an analysis for a very similar constraint on the occurrence of German $z u$-infinitives in (20). This analysis applies straightforwardly to the facts in (28). The claim is that once the overt C-element bole is missing, the $\mathrm{C}$-slot will be filled by I-to-C movement much like the movement of $\mathrm{V}+z u$ to $C$ which we have seen in (12). According to this analysis (28d) is assigned the S-structure:

ami $\left[{ }_{C P}(s p e c)\left[C_{C^{\prime}}\left[I_{P}\right.\right.\right.$ babul $\left[_{I^{\prime}}\left[{ }_{V P}\right.\right.$ ruTi $\left.\left.e_{i}\right]\left[_{I} e_{i}\right]\right]$ kha-be $\left.\left.\left.e_{i}\right]\right]\right]$ Sune-chilam

The verb of the embedded clause appears to be adjacent to the matrix verb, thus giving rise to a proper head/head relation. $(28 \mathrm{c})$ is barred because the extraposed material prevents such a relation, and - according to the present analysis - the embedded $\mathrm{CP}$ remains invisible to the matrix verb. Cases such as (28b) are, of course, unaffected by rightward displacement, 
since here it is the left edge of the $\mathrm{CP}$ that must be identified by the verb.

Let us now see how the visibility condition developed for the German data can be applied to Bengali. One difference is that we have not seen a single instance of a filled specifier of $C$. The reason for this is that Bengali is neither a V2- nor a WH-movement-language (in the sense of overt movement to Spec-CP). We still want to say that Bengali moves WHelements in LF, and that the WH-operator moves to or through Spec-CP. Another difference is that there is no indication of an NP-over-S strategy, which may be a consequence of the nature of the complementizers. Bole would not qualify, because it is [+V]; and since the complementizer je never arises on the Case-marking side of $\mathrm{V}$ i.e. to the left of it, there does not seem to be any motivation for this strategy whatever the features of $j e$ are. Following (13), we may then state C-visibility for Bengali as a condition on LF as in (30).

(30) $\mathrm{C}$ is visible for its governor $\mathrm{V}$ at LF iff any of (i) through (iii) holds: (i) $\mathrm{V}$ governs a trace of $\mathrm{CP}$, (ii) $\mathrm{V}$ is head-adjacent to C, (iii) due to SHA a feature appears on Spec-CP which satisfies V's s-selection requirements.

We have seen in this section that the syntax of Bengali, another SOVlanguage, offers reasons to believe that our generalization about C-visibility in German went in the right direction. Let me finally note that the presence of two distinct complementizer-like categories which appear in complementary distribution with respect to the positioning of the $\mathrm{CP}$ can also be observed in other SOV-languages which are outside the scope of the present investigation. ${ }^{32}$

\section{THE SCOPE OF WH}

I have argued so far that finite CPs shift to a quasi A-position to the right of the verbal complex, and that WH-movement starts from a CP in this derived position and proceeds cyclically from Spec-CP to Spec-CP. Given the above discussion of CP-licensing in Bengali, we should expect roughly the same to be true in this language. Notice, however, that Bengali is primarily a WH-in situ language. In this section, I want to discuss some aspects of WH-scope that pertain to the question of where CPs originate in Bengali and closely related Indian languages.

\subsection{Overt Wh-Movement}

Let us begin with the unusual case. I have said before that Bengali is a WHin situ language. It differs, however, from the Far-Eastern languages in 
also allowing overt movement (as a less prominent option). The same has repeatedly been reported for Hindi. ${ }^{33}$ Consider the Bengali example in (31), the Oriya examples from Bal (1990) in (32), and the Hindi example from Srivastav (1991b) in (33).

$$
\begin{aligned}
& \text { tumi [ki OSukh -e }]_{i} \text { bhab-cho }\left[{ }_{C P} e_{i}\left[C_{C^{\prime}} \text { je }\right]\right. \\
& \text { you which illness-[loc] think-[pres] } \\
& \text { that } \\
& \text { [IP ram } \left.\left.e_{i} \text { mara } g E-c h e\right]\right] \\
& \text { Ram die go-[past] } \\
& \text { 'Of which illness do you think that Ram died?' }
\end{aligned}
$$

(32) a. kaahaaku $u_{i}$ tume bhaabucha [jadu $e_{i}$ maarithilaa]?

whom you are-thinking Jadu had-beaten

'Who do you think Jadu had beaten?'

b. kie ${ }_{i}$ tume bhaabucha [je $e_{i}$ raamaku saahaajya kariba]? who you are-thinking that Rama help will-do

'Who do you think will help Rama?'

$$
\begin{aligned}
& \text { kyaa }_{i} \text { tum jaante ho [ki usNE } \mathrm{e}_{\mathrm{i}} \text { kiyaa]? } \\
& \text { what you know that he did } \\
& \text { 'What do you know that he did?' }
\end{aligned}
$$

If one assumes that the embedded $\mathrm{CP}$ is in an extraposed position i.e. in an $\mathrm{A}^{\prime}$-position, WH-movement should be impossible. Contrary to this expectation, however, the examples in (31) through (33) are grammatical. In order to account for (33)'s grammaticality, Srivastav (1991 a,b) as well as Mahajan (1990) suggests that movement of kyaa takes place from a D-structure in which the CP is in c-governed position, and that this process is followed by extraposition to a righthand $A^{\prime}$-position. We have seen that this would lead to undesirable consequences in German. I would like to point out one problem with this kind of analysis: ${ }^{34}$ Bengali and most related languages permit extraposition of NPs and some other constituents. At the same time, Bengali does not observe the Left Branch Constraint of Ross (1967), i.e. an NP can split up such that the possessor part scrambles leftwards as shown in (34).

(34) kon lok -Ta $-r_{i}$ tumi [ $e_{i}$ notun bari] dekhe-cho? which man-[cl]-[poss] you new house see -[past]

'Which man's new house have you seen?'

If remnants of WH-movement can be extraposed, we expect that such an operation will leave grammaticality unaffected. However, it does not, as the following example shows.

(35) * kon lok-Ta- $r_{\mathrm{i}}$ tumi $\mathrm{e}_{\mathrm{j}}$ dekhe-cho [ $\mathrm{e}_{\mathrm{i}}$ notun bari $]_{\mathrm{j}}$ ? 
Similar considerations hold for all the familiar cases from English and the West Germanic languages, in which the trick of remnant movement to the right would undermine the generally observed freezing effect. Thus, I believe that the old-style extraposition analysis not only is blind to the phrasal architecture of the governee, but also, in order to reach descriptive adequacy, would have to add undesirable power to the grammar of movement. The alternative is that C-initial CPs in Bengali, Hindi, Oriya etc. must shift to a clause-final A-position, and that WH-movement can proceed from there.

\subsection{WH-Movement at $L F$}

One major argument in favor of the traditional extraposition account of Bengali and Hindi complementation seems to be that extraposed CPs are scope islands. Bengali is even a nicer test case than Hindi because it allows tensed CPs to remain in c-governed position. Consider the following contrast of scope ambiguity.

(36)

$$
\text { ora [ke as -be] Sune-che }
$$
they who come-[fut] hear-[past]

ambiguous

i. 'They have heard who will come'

ii. 'Who have they heard will come?'

b. ora Sune-che [ke aS-be]

unambiguous

i. 'They have heard who will come'

ii. NOT: 'Who have they heard will come?'

When the $\mathrm{CP}$ is in a c-governed position as in (36a), ke is allowed to take the lower or the higher Spec-CP as its ultimate landing site. When the CP is to the right of $\mathrm{V}$, only narrow scope is allowed..$^{35} \mathrm{~A}$ theory in which the righthand $\mathrm{CP}$-complement has been extraposed to an $\mathrm{A}^{\prime}$-position predicts this asymmetry straightforwardly as a CED-violation. Thus contrary to the evidence we have adduced above in favor of a righthand A-position, it seems that the traditional extraposition analysis is still needed. Given what we have said so far, we are faced with a paradox. I will next give a sketch of how this paradox can be resolved in favor of my general account of $\mathrm{CP}$-licensing in SOV-languages.

\section{DOMAIN EXTENSION IN SYNTAX AND AT LF}

As I have shown in Bayer (1990a), Koster's (1987) theory of domain extension can be used to determine the scope of logical operators such as WH-phrases and quantified NPs (of a certain kind). The important insight here is that the notion directionality of government plays a central role in the determination of movement and scope. The following definitions present a generalized and updated version of the account found in Bayer (1990a). 
The standard assumption is that every maximal category is a potential barrier and that there are several ways to dissolve the barrier status. As Cinque (1990: ch. 1) has argued, it may be necessary to distinguish between barriers for (antecedent) government and barriers for ("referential") binding. The following definition ignores the additional properties of the latter. ${ }^{36}$

Barrier for government (antecedent government)

$\mathrm{XP}$ is a government barrier for YP iff (i) or (ii) holds:

i. $X P$ is not directly selected by a head

ii. $\mathrm{X}^{\prime}$ includes $\mathrm{YP}$, and $\mathrm{X}$ is a lexical head that selects $\mathrm{YP}$ in the non-canonical direction

\section{Inclusion}

$\mathrm{XP}$ includes $\mathrm{Y}$ iff $\mathrm{Y}$ is dominated by $\mathrm{X}^{\prime}$

(38) means that something in the specifier of XP or in a segment of (i.e. adjoined to) XP will not count as included. Certain conditions have to be added to (37) to make this concept of barrier applicable to a broad range of extraction phenomena found in German. I will concentrate here on only the core case of extraction from a complement CP and from VP. (37) predicts among other things that extraction of something included in $V^{\prime}$ from $V P$ is possible only if $\mathrm{V}$ governs it in the canonical direction i.e. in German to the left. I assume that VP does not have an $\mathrm{A}^{\prime}$-specifier, and that movement from a VP-adjoined (scrambling?) position to an operator position would be in conflict with principles of chain homogeneity. ${ }^{37}$ Combining this with (38), a phrase included in $\mathrm{V}^{\prime}$ on the righthand side cannot be extracted from VP. Consider now the necessity of shifting CPs of a certain kind to the right of $\mathrm{V}$, although the language in question follows the parameter of head-finality (at least with respect to the verb's orientation). The result of this shift is a dead end both for extraction from CP and extraction of CP itself. ${ }^{38}$ This concept of barrier allows us to derive the data in (36) without recourse to the idea that an extraposed CP is in an adjoined position. The explanation goes as follows: In (36a), they [ ${ }_{\mathrm{CP}} \mathrm{IP}_{\mathrm{P}}$ who come-will] $]$ heard, who can move to Spec-CP and stop there. This derives the narrow scope reading; it can alternatively move on to Spec-CP of the matrix-CP, because the matrix-V c-governs $\mathrm{CP}$. This derives the direct question reading. In the shifted version (36b), they heard [CP[IP who come-will] ], the narrow scope reading can equally be derived, but the step from Spec-CP across the matrix-VP is not permitted. This precludes the direct question reading. ${ }^{39}$

This brief sketch of WH-scope at LF has given an idea how the island effect of rightwards governed complements can be derived with a minimum of technical machinery. But recall now that one of the main empirical reasons for assuming $\mathrm{CP}$-shift to a quasi $\mathrm{A}$-position has been that overt extraction can proceed from it both in Bengali and in German. Precisely 
this result would become unavailable if this were all that had to be said. The problem is that we have failed so far to draw a difference between LF-movement and overt movement. To make this difference clear, let me illustrate the immediately plausible situation in sentence processing: When processing a sentence with overt WH-movement, the first information the parser receives is that it is dealing with a constituent question. Similarly in a case of overt movement in Bengali, the matrix clause contains - even if not in Spec-CP - a constituent that invariably turns the clause into an interrogative. Nothing like that can happen for trans-clausal LF-movement. Before the WH-phrase in situ is encountered, nothing signals to the processor that the entire structure will count as a question. In this case, the path from the WH-item in situ to its ultimate scope position has to be computed on phrase structure pure. I would like to use this intuition about syntactic processing for developing an account for overt movement in these languages.

If we follow Chomsky (1993), there must be a phonetically induced (morphology related) reason for overt movement. If there were no such reason, movement would be invisible. Under the standard view that quantified expressions need scope, the driving force behind Quantifier Raising $(\mathrm{QR})$ and WH-movement would be semantic necessity. Under the hypothesis that invisible movement is "cheaper" than overt movement it follows in Chomsky's theory that any movement is procrastinated to LF unless there is a morphological trigger which forces movement in order to satisfy requirements of the phonetic-acoustic interface of the grammar. This means that there cannot be optional overt WH-movement in the traditional sense, but only attraction of a WH-phrase by a WH-feature for the purpose of turning it into a legitimate PF-object. Under this view it is understandable that movement of a WH-phrase is but one possibility. Pure interrogative features as S-structure signals for scope association are found in various languages. ${ }^{40}$ (37) reflects the general situation that holds without the involvement of attraction. The overt movement case - which I take to be special - is captured by the following condition:

$$
\begin{aligned}
& \text { Debarrierization by Attraction } \\
& \text { XP fails to be a government barrier for } \mathrm{YP} \text { if } \\
& \text { i. X directly governs } \mathrm{ZP} \\
& \text { ii. YP can move to an } \mathrm{A}^{\prime} \text {-operator position of } \mathrm{ZP} \\
& \text { iii. XP is c-commanded by a feature } \Psi \text { such that YP is } \\
& \text { attracted by } \psi \text { for checking }
\end{aligned}
$$

Take XP to be VP where V governs a CP to its right. Then VP may fail to be a barrier for a WH-phrase if VP is c-commanded by a WH-feature that attracts the WH-phrase for checking. My claim is that the directionality barrier VP can only be crossed in the presence of an external S-structure trigger. This solution is reminiscent of Koster's (1987: 194) suggestion 
that in the case of extraposition the matrix verb governs exceptionally to the right, and that the usual directionality constraint is suspended. ${ }^{41}$ In this theory, cyclic WH-movement cannot be analyzed as it is usually done for head-initial languages like English, Romance, Scandinavian etc. Koster proposes that WH-movement in Dutch and German is only the sum of a number of local i.e. CP-internal, movements. Long WH-movement thus amounts to the "compounding" of short movements that are licensed by the directionality constraint, while the process of compounding itself is not subject to it. My own account is not only an elaboration of Koster's insight about cyclic movement in Dutch and German, but also captures the WH-scope facts of typologically weakly related languages like Bengali in a natural way. In addition, it opens up an explanation of a most peculiar difference between Dutch and German on the one hand and the Germanic VO-languages as well as Romance, Hebrew etc. on the other, all of which show more or less tolerable WH-island violations. Dutch and German, however, exhibit intolerance WH-island effects when WH-phrases are extracted from WH-complements. ${ }^{42}$ I agree with Bennis and Hoekstra (1984) and Frampton (1990) that the reason for this must be sought in the fact that (a) the WH-CP is governed at the "wrong" side, and that (b) the insertion of an intermediate trace is absolutely essential in order to cross the CP-barrier. The Head Government Condition on Adjunction (HGCA) of Frampton (1990: 53) states that adjunction of a WH-phrase (during a Barriers type derivation) to VP is only licit from a position that is c-governed by V. Hence VP becomes a barrier for movement from CP unless Spec-CP contains a trace. Precisely this is not possible in WH-CPs. Application of the HGCA to LF-movement (which Frampton does not talk about) would make an incorrect prediction for the extraposed WH-in situ case of Bengali in (36b) they heard [ $\mathrm{CP}_{\mathrm{IP}}$ who come-will]], but (37) and (39) can achieve the desired result for these as well as predict the special status of WH-islands in extraposing SOV-languages.

Let me finally mention that the strict ban against WH-island violations in Dutch and German presents another piece of evidence against the idea of "orderly" WH-movement and subsequent remnant extraposition of $\mathrm{CP}$ to an $\mathrm{A}^{\prime}$-position. Domain extension out of a c-governed WH-island should yield precisely the same strength of a subjacency violation, as it does in English and other head-initial languages. Extraposition of the remnant $\mathrm{CP}$, being something like a "stylistic" operation, would not interfere with the licensing of the WH-traces. In the worst case, the extraposed CP could reconstruct into its D-structure position and thus erase any of the distinctions observed. In the theory presented in this article, extraposition is not an accidental process; it rather takes place in order to make clausal arguments of a certain kind visible. This process, however, suffers from the disadvantage that it bleeds certain options that exist in languages in which sentential complementation does not interfere with the verb's orientation. 


\section{SUMMARY}

The investigation presented in this article took its start from the tension that exists between the UTAH and the fact that SOV-languages like German and Bengali have sentential arguments that regularly appear on the right side of the verb. I have suggested a number of licensing conditions for $\mathrm{CP}$ which crucially refer to visibility under head/head adjacency. Under normal conditions my account requires $\mathrm{C}$-initial $\mathrm{CP}$ to extrapose in order to become visible as an argument. It has, however, been shown that extraposition in this sense cannot be couched in the traditional theory of $\mathrm{A}^{\prime}$-movement. I have suggested instead that extraposition is an operation of argument shift. This is consistent with the fact that movement from extraposed CPs is possible. On the other hand, argument shift to the noncanonical side of the verb destroys the formation of an extraction path along the lines of canonical government. It was shown that this theory makes correct predictions about abstractly represented (LF-derived) WH-scope in Bengali (and similar languages), and that scope extension from a $\mathrm{CP}$ in the derived context [ $\left.\mathrm{V}_{-}\right]$(i) needs a morphological trigger and (ii) can only proceed in successive cyclic moves.

\section{ACKNOWLEDGEMENTS}

Between 1990 and 1993 earlier stages of this research were presented in talks at the Max-Planck-Institute of Psycholinguistics, Nijmegen, at the Universities of Massachusetts (Amherst), Cologne, Düsseldorf, Tübingen, at CNRS Paris, and at the 1991 Summer School on Generative Grammar and the Grammar of Slavic Languages in Dubrovnik. For discussion of issues connected with this research I am grateful to Markus Bader, Jogamaya Bayer, Ellen Brandner, Alice Davison, Arnold Evers, Hubert Haider, Jack Hoeksema, Celia Jakubovicz, Hans-Peter Kolb, Jaklin Kornfilt, Aditi Lahiri, Anoop Mahajan, Judith Meier, Gereon Müller, Hans-Georg Obenauer, Eric Reuland, Henk van Riemsdijk, Tom Roeper, Veneeta Srivastav, Wolfgang Sternefeld, Sten Vikner and Jürgen Weissenborn. Special thanks to Probal Dasgupta, without whose guidance I could not have dared to touch Bengali. All remaining errors are mine. The Nederlandse Organisatie voor Wetenschaplijk Onderzoek (NWO) supported this research by awarding to me a four months stipend in 1991 at the Rijksuniversiteit Groningen.

\section{NOTES}

I See Greenberg (1963), Mallinson and Blake (1981). Generative analyses as early as Bach (1962) and Bierwisch (1963), however, recognized and always emphasized the basic SOVorder that surfaces in clauses that are introduced with a complementizer. See also Koster (1975), who addresses the order of constituents in Dutch explicitly.

2 Hoekstra (1984: 85) states the UCC as follows: "At S-structure, no element of [ $\alpha \mathrm{N}, \beta \mathrm{V}]$ 
may govern a projection of $[\alpha \mathrm{N}, \beta \mathrm{V}]$." Hoekstra assumed at that time that the head of $\mathrm{S}^{\prime}$ $(C P)$ is $[-N,+V]$. We would still subscribe to this view, but only for cases where I (actually $\mathrm{V}+\mathrm{I}$ ) moves to $\mathrm{C}$. One empirical goal for Hoekstra was to find a reason why Dutch dat-CPs should undergo extraposition instead of remaining where they are generated.

3 One of Fanselow's examples is a case of VP-topicalization from which a WH-phrase has been stranded:

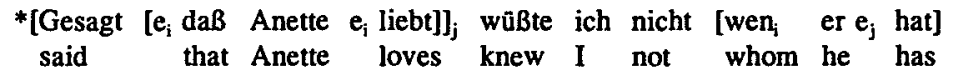

intended: 'I would not know who(m) he said that Anette loves'

The reason for the ungrammaticality is obviously that the VP-chain interferes with the WHchain; see Müller and Stemefeld (1993) for detailed discussion of unambiguous binding.

4 The issue is too intricate to discuss in detail here. One suggestion for German V2 (see von Stechow and Stemefeld 1988: 399f) that does not refer to the ECP is that there is a feature clash because V2-clauses are $[+\mathrm{V}]$, while $e s$ is $[+\mathrm{N}]$. Notice, however, that V2-clauses are licensed after pronominal adverbs i.e. in a position which is certainly an $\mathrm{A}^{\prime}$-position (as shown by its islandhood):

(i)

$$
\begin{aligned}
& \text { weil er }\left[{ } _ { \mathrm { PP } } \text { da'mit] gerechnet hat } \left[\mathrm{CP}_{\mathrm{i}}\right.\right. \text { man würde ihn befördern] } \\
& \text { because he there +on counted has one would him promote } \\
& \text { 'because he thought that one would promote him' }
\end{aligned}
$$

Cinque (1989) suggests that $d a$ is not in an A-position, and that the V2-CP could reconstruct into an empty A-position to the right of $P$. This proposal is problematic for various reasons, the most serious being that there should be reconstruction into a trace from the right periphery; (see Bayer (1990a) for arguments against such a view). I would tentatively suggest that da differs from es in being underspecified for the nominal feature. Assume now that postpositional $\mathrm{P}$ as in (da)mit is strictly subcategorized by the verb, and that $\mathrm{P}+\mathrm{V}$ retains the verb's potential to license a Case, which here would be a "verbal Case". Since da (as opposed to es) is not able to receive Case, although it occupies an A-position (in Spec-PP), this potential is transmitted to the phrase coindexed with da. Notice that da being categorically underspecified will be compatible with $[+\mathrm{V}]$ and as such permits coindexation with a V2-clause.

$s$ Bennis and Hoekstra (1989) propose that extraposition and verb raising is forced by $T(e n s e)$ Linking. According to their theory a verb has to be identified by a tense operator. Similarly, the tense of an embedded clause has to be connected to the tense of its governing domain. For [CP, VP] T-linking can only be achieved if V moves to the T-head, and the CP becomes a sister of a chain link of the matrix T-chain. Unfortunately it also remains unclear how this theory could deal with German infinitival constructions as well as with the Bengali cases that will be discussed in section 4; see also Reuland (1991).

6 The intervention of auxiliaries between $\mathrm{V}$ and $\mathrm{CP}$ ceases to be a problem if one realizes that auxiliaries and modals are (V-)raising verbs. It is not essential here whether V-raising is taken to be incorporation as in Baker (1988) or formation of stacked categories as in Bayer (1990a) and Bayer and Kornfilt $(1990,1994)$. In each case it can be guaranteed that a righthand $\mathrm{CP}$ formally turns out to be a sister of the licensing verb.

7 This is reminiscent of Safir's (1982) idea that each CP must have a unique governed head and that I-to-C can make I visible to government from outside; SHA still seems to be indispensable, however, as we will see immediately.

8 We will turn to this below.

9 Cf. Koperberg (1987) and Veld (1993) for Dutch.

10 The verb drängen ("urge"), for example, is not a restructuring verb, and is thus likely to govern a $\mathrm{CP}$. Notice that $\mathrm{CP}+\mathrm{V}$ can still topicalize to $\mathrm{Spec}-\mathrm{CP}$, which is a good indica- 
tion that CP has remained in situ, while remnant topicalization as in (ii) is bad, which indicates that drängen does not permit clause union:

(i) [vp [CP PRO zu bleiben] gedrăngt]] hat sie ihn bestimmt nicht to stay urged has she him certainly not

'She has certainly not urged him to stay'

(ii) *[ $e_{i}$ zu bleiben gedrängt $]$ hat sie ihn [bei ihr $]_{i}$ bestimmt nicht to stay urged has she him with her certainly not

'She has certainly not urged him to stay with her'

1 NP-over-S looks parochial and, at first sight, seems to violate $X^{\prime}$-syntax. But this is not actually the case. Webelhuth (1989: ch. 4) has argued convincingly that daß is $[+N]$, and that only (embedded) V2-clauses are [+V]. If he is right, this would speak against the UCC for obvious reasons, and at the same time it would be possible to supply CP with an NP. shell because there would be no feature clash.

12 Cf. Haider (1990).

13 Thanks to Probal Dasgupta and Henk van Riemsdijk, who drew my attention to these and similar facts in Bengali and German respectively.

14 Similar facts involving rightwards moved categories have been reported in the literature on other head-final languages. Hasegawa (1990) gives the following examples of right dislocation from Japanese:

(i) a. John-ga $\mathrm{e}_{\mathrm{i}}$ tabeta yo susi $-\mathrm{o}_{\mathrm{i}}$ John-NOM ate sushi-ACC

$\begin{array}{cclll}\text { b. * Mary-ga } & \text { [John-ga } & \mathrm{e}_{\mathrm{i}} \text { tabeta yo } & \left.\text { susi }-\mathrm{o}_{\mathrm{i}}\right] & \text { to omotteiru } \\ \text { Mary-NOM } & \text { John-NOM } & \text { ate } & \text { Sushi-ACC } & \text { C is-thinking }\end{array}$

The following Turkish data from Kornfilt (1990) show similar cases of rightward movement (referred to as 'leaking' or 'toppling'):

(ii) a. [Herkes [Ahmedin $e_{i}$ aşik olduğunu] biliyor] teyzesine everybody Ahmet in-love-be knows with-his-aunt

'Everybody knows that Ahmet is in love with his aunt'

b. *Herkes [[Ahmedin $e_{i}$ aşik olduğunu] teyzesine $\left.e_{i}\right]$ biliyor

See also Kural (1992) for similar observations.

is In a talk at the Germanic Comparative Syntax Workshop, Tromsø 1992, Mark Lencho independently argued that English to is in C.

$16 z u$-Infinitives to the right of $\mathrm{V}$ must - according to my view - be in an A-position because one can extract WH-phrases from them, and one can, in the presence of certain matrix verbs, even scramble definite NPs into the matrix-IP (see Bayer and Kornfilt 1990, 1994). For $z u$-infinitives to the right of $\mathrm{V}$ which are not subject to clause union effects I assume a CP-structure roughly as in (i).

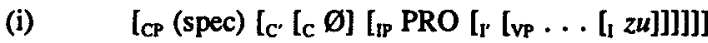

Various speculations come to mind as to why after $V$-to-I $z u+V$ may not move to $C$ as is the rule in V2-sentences, but I will not try to pursue them here.

17 The position of Spec-CP is irrelevant for my purposes. I assume its potential existence because one can extract from infinitival CPs rather freely. Notice, however, that in German there is no overt syntactic evidence comparable to Spec-CP in tensed CPs e.g. it is not a possible landing site for WH. One may see a problem for the attachment of the extraposed relative clause in (1le). Movement would have to cross at least one barrier. Notice that the 
extraposition of argument CPs from such contexts is quite bad. This suggests that the relative clause is not licensed by movement, a view that is familiar from the literature (see Culicover and Rochemont 1990).

I8 Notice that we cannot use SHA here, even if we were able to show that $z u$-infinitives have a righthand Spec-CP. The extraposed material cannot be in Spec-CP for the simple reason that extraposition where grammatical never blocks WH-movement.

19 With data of a rather different kind in mind (mainly restrictions that hold in various languages between prenominal adjective and noun as well as noun and postnominal genitive), van Riemsdijk (1992) characterizes head adjacency as follows.

(i) a. $*\left[\mathrm{XP} \ldots \mathrm{X}^{\circ} \mathrm{W}_{1}\right] \mathrm{W}_{2} \mathrm{H}^{\circ}$ unless $\mathrm{W}_{1}, \mathrm{~W}_{2}=\emptyset$

$$
\text { b. }{ }^{*} H^{\circ} W_{2}\left[x p W_{1} X^{\circ} \ldots\right] \text { unless } W_{1}, W_{2}=\emptyset
$$

The German data considered here exemplify a case of violation which can be couched in the filter (ia) as shown in (ii).

(ii) $\quad *\left[\left[x p \ldots X^{\circ}\right] W_{1}\right] H^{\circ}$ where some phrase $W_{1}$ is adjoined to XP (see (11d)).

(ii) may be taken as an instance of a head adjacency violation, depending on our assumptions about the position of Spec-CP. Notice that there is no indication that the intervention of $\mathrm{W}_{2}$ could affect the licensing of $\mathrm{CP}$ as long as the $\mathrm{CP}$ is scrambled, topicalized or visibly extraposed, (though it does in some of the cases van Riemsdijk considers).

20 See Mahajan (1990), where this notion is employed for certain kinds of scrambling.

${ }^{21}$ This is essentially Baker's (1988: 64) Government Transparency Corollary, which says that a lexical category which has an item incorporated into it governs everything the incorporated item had governed in its original position.

22 See Chomsky (1993) for the theoretical background of this notion.

23 Cf. Bayer (1990a).

24 Following a suggestion by Probal Dasgupta, I will adopt the following conventions for the transcription of Bengali: $T, D$ for retroflex stops, $c, j$ for palatal stops, $S$ for a palatoalveolar fricative, $\mathrm{N}$ for a velar nasal, $\mathrm{Y}, \mathrm{W}$ for mid and $\mathrm{y}, \mathrm{w}$ for high semi-vowels, $\mathrm{E}, \mathrm{O}$ for low vowels; $M$ indicates the nasal quality of a preceding vowel; after a consonant, $h$ indicates aspiration. [cl] stands for nominal classifier. For the representation of examples from other Indian languages I follow the sources from which I drew them.

25 For relevant discussion see Singh (1980), Dasgupta (1980, 1984, 1987), as well as Bal (1990) on Oriya, a closely related language spoken in the state of Orissa i.e. in the immediate vicinity of West Bengal. What I have to say here is mainly based on these works. I will refer to both elements as complementizers, although this may ultimately turn out to be too gross a simplification.

${ }_{26}$ Indo-Aryan languages such as Bengali, Marathi, Oriya etc. are likely to have borrowed this use from Dravidian; cf. Telugu -ani, Tamil endru, Kannada anta, Malayalam -ennə, all of which are clause-final.

27 In his study of complementizers in Oriya, Bal (1990) gives examples of extraposed CPs which are headed by the final complementizer boli. He seems to take these as grammatical, but then adds that they are "not typical" and that they "usually occur in situ, in the expected pre-head complement position, ..." (pp. 6f). Alice Davison (p.c.) informs me that C-final clauses can occasionally be extraposed in Dravidian. For my argumentation this is not relevant as long as these extrapositions have a marked character. Notice that je-clauses and German daß-clauses never have a marked character.

${ }_{28}$ One problem to which we cannot tum here is that je-initial CPs are always impossible unless the CP appears in extraposed position. In this way it clearly differs from German daß. Dasgupta's (1987) suggestion that je may be banned from first position because it is an enclitic does not help, because it does not encliticize when CP is extraposed. I tend to believe that the free availability of head-final CPs (with bole- or zero-C) has given rise to 
a situation in which je-initial CPs are never generated to the left of the verb. Here, the system seems to have radically departed from head finality.

29 Bal (1990) argues that je is never a complementizer. He suggests that it is some kind of WH-element that has to be coindexed with an operator for "emphasis" when the je-CP is to the left of the verb, while $j e$ has to undergo WH-movement when the $\mathrm{CP}$ is extraposed. In Bal's analysis this is so, because $j e$ has to be coindexed with the trace of $\mathrm{CP}$ or pro. For the extraposition case he proposes the structure in (i):

$$
\text { [IP } \left.\left.\ldots \mathrm{e}_{\mathrm{i}} / \mathrm{pro}_{\mathrm{i}} \mathrm{V} \text { lCP }_{\mathrm{Ce}} \mathrm{j}_{\mathrm{i}}\left[_{\mathrm{C}} \emptyset\left[_{\mathrm{IP}} \ldots \mathrm{e}_{\mathrm{i}} \ldots .\right]\right]\right]\right]
$$

At least five questions arise from this analysis. First, it is unclear what $j e$ binds. If it does not bind anything, the structure would be ruled out as a case of vacuous quantification; second, if je is a WH-item, how is it possible that a "believe"-type verb (Oriya bhaab-) can c-select a je-CP? Third, as Bal himself notices, Oriya does not tolerate WH-island violations. Therefore he has to assume a second specifier position in order to allow extractions from je-clauses which do occur in this language (see also section 5 of this article). Fourth, it remains unclear how WH-extraction from CP could be possible at all, given that CP is in an extraposed position and should thus behave like an island. Fifth, although $j e$ must be (historically) related to the relativization operator of non-correlative relatives, this cannot be a reason for functionally identifying the two. Notice that complementizers in Germanic (that, dat, daß etc.), Romance (che, que etc.), Slavic (shto, co etc.) and Greek (oti) clearly derive from WHoperators, while it would be hard to argue that they function as WH-operators in the modern languages. I assume that the same reasoning applies to the grammars of modern Bengali and Oriya.

30 Something to this extent has explicitly been stated in Sinha (1990). Head/head adjacency does, however, not mean that the CP-complement is immobile. As (i) and (ii) show, both types of CPs can shift in their respective domains to the left or to the right of the verb:

(i)

$$
\begin{array}{llllll}
\text { chele-Ta } & \text { Sune-che } \mathrm{e}_{\mathrm{i}} & E k & \text { ghonTa age }[\mathrm{cP} \text { je or baba aS -be }]_{\mathrm{i}} \\
\text { boy -[cl] hear-[past] one hour ago that his father come-[fut] }
\end{array}
$$

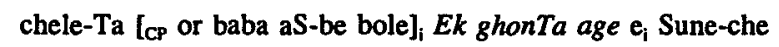

31 This has been pointed out to me by Probal Dasgupta (p.c.); see also footnote 13. For important related observations see Dasgupta (1993).

32 For Marathi and Kashmiri cf. Wali (1988). Turkish has final complementizers like -dik and $-m A /-m A k$ alongside the initial $k i$ which has been borrowed from Persian (see Underhill (1976), Kornfilt (1984), Kural (1992) and Veld (1993: ch. 7), among others). Koopman (1984: ch. 3) observes that in the head-final language Vata the final complementizer $k a$ appears only in the context $[\mathrm{CP} \ldots k a] \mathrm{V}$, whereas the initial C-like element $n a$ ("to say") always must precede an extraposed clause. Koopman argues against taking na as a complementizer, but her own analysis (p. 96) is not quite compatible with modern $X^{\prime}$-syntax, where functional elements head their own projections.

33 See Davison (1988), Mahajan (1990: ch. 3), Sinha (1990), Srivastav (1991a: ch. 7, 1991b) and others. These works show that there is long scrambling of NP which may even lead to a Case position, as has been observed in many languages (including certain varieties of British English, Mark Steedman (p.c.) - e.g. This is the man whom I believe went to the post office; Richard Kayne (p.c.) informs me that for English the original observation is due to Otto Jespersen).

34 Another problem is pointed out at the end of section 6.

35 Observations to this effect have independently been made by Wali (1988) about Marathi and Kashmiri; to my knowledge Wali is the only researcher who has tried to explain the left/right asymmetry in terms of Connectedness Theory (Kayne 1983). 
36 The following additional definitions incorporate Chomsky's (1986) notion of Barrier as well as Rizzi's (1990) notion of Relativized Minimality.

(I)

\author{
Government \\ $\alpha$ governs $\beta$ iff \\ (i) $\alpha$ c-commands $\beta$ and \\ (ii) there is no $\gamma, \gamma$ a barrier for $\beta$ and \\ (iii) Relativized Minimality is respected
}

(II)

\title{
C.Command
}

$\alpha$ c-commands $\beta$ iff $\alpha$ does not dominate $\beta$, and every $\gamma$ that dominates $\alpha$ also dominates $\beta$

(I) guarantees that $\alpha$ cannot govern $\beta$ when a barrier $\gamma$ intervenes and/or there is an intervener $\delta$ which is of the same syntactic/semantic type ( $\left.A^{\prime}, A, X-z e r o\right)$ as $\alpha$.

37 See Chomsky (1986: 73 ff) and Müller and Sternefeld (1993).

38 Notice that this yields an explanation for the ill-formedness of (19c); it also accounts for the fact that Dutch and German PPs are barriers for extraction unless they have a specifier (that hosts a so-called $R$-pronoun); the reason is that $\mathrm{P}^{\prime}$ includes DP on the right side.

39 Veneeta Srivastav (p.c.) suspects that bole is not a complementizer, and that sentences with bole do not allow for a narrow scope reading. The latter is indeed the case. The following sentences differ with respect to the scope of kothay ("where"):

(i) ram [kothay ja-be] likhe-che

Ram where go-[fut] write-[past]

a. Ram wrote where he will go

b. Where did Ram write he will go?

(ii) ram [[kothay ja-be] bole] likhe-che

a. (not available)

b. (same as in (i))

I think that there is still no reason to assume that bole is not a complementizer. Our discussion of German has shown that V2-complements cannot have a [+WH]-phrase in Spec-CP $($ SpecV +1$)$, and we have argued that this may be due to a feature clash for SHA. Given that bole ("having said") is a verbal form (which even seems to have retained its semantic transparency for the speakers), SHA would make the same prediction for Bengali. Intermediate traces, on the other. hand, do not leave features in Spec-CP (see Lasnik and Saito 1984). Therefore, the wide scope construal is possible.

40 Some Indo-European and non-Indo-European languages use interrogative pronouns meaning "what" as scope markers; Japanese uses the clause-final particles $k a$ and $m o$.

41 Koster (1987: ch. 4) captures directionality of government with a uniformity condition which he calls the Condition of Global Harmony; see also Bayer (1990a).

42 See among others Koster (1978, 1987), Bennis and Hoekstra (1984), van de Koot (1988), Frampton (1990), Bayer (1990b), Cinque (1990: 169) and Sternefeld (1991). The restrictions are relaxed when referential topic objects are extracted; cf. Fanselow $(1987,1990)$, Bayer (1990b), Sternefeld (1991) and Müller (1993: ch. 6).

\section{REFERENCES}

Bach, Emmon: 1962, 'The Order of Elements in a Transformational Grammar of German', Language 38, 263-269.

Baker, Mark: 1988, Incorporation: A Theory of Grammatical Function Changing, University of Chicago Press, Chicago. 
Bal, Bijoy Kumar: 1990, COMP and Complementizers in Oriya and English, Doctoral dissertation, Central Institute of English and Foreign Languages, Hyderabad.

Bayer, Josef: 1990a, Directionality of Government and Logical Form: A Study of Focusing Particles and WH-Scope, Habilitation thesis, Universität Konstanz.

Bayer, Josef: 1990b, 'Notes on the ECP in English and German', Groninger Arbeiten zur Germanistischen Linguistik 30, 1-55.

Bayer, Josef and Jaklin Kornfilt: 1990, 'Restructuring Effects in German', in Engdahl, Reape, Mellor and Cooper (1990), pp. 21-42.

Bayer, Josef and Jaklin Kornfilt: 1994, 'Against Scrambling as Move-Alpha', in N. Corver and H. van Riemsdijk (eds.), Studies on Scrambling, de Gruyter, Berlin.

Bennis, Hans: 1986, Gaps and Dummies, Foris, Dordrecht.

Bennis, Hans: 1989, 'Why Kaatje Was Not Heard Sing a Song', in Jaspers, Klooster, Putseys and Seuren (1989), pp. 21-40.

Bennis, Hans and Teun Hoekstra: 1984, 'Gaps and Parasitic Gaps', The Linguistic Review 4, 29-87.

Bierwisch, Manfred: 1963, Grammatik des deutschen Verbs, Akademie-Verlag, Berlin.

Chomsky, Noam: 1986, Barriers, MIT Press, Cambridge, Massachusetts.

Chomsky, Noam: 1993, 'A Minimalist Program for Linguistic Theory', in K. Hale and S.J. Keyser (eds.), The View from Building 20: Essays in Linguistics in Honor of Sylvain Bromberger. MIT Press, Cambridge, Massachusetts, pp. 1-52.

Cinque, Guglielmo: 1989, 'On Embedded Verb Second Clauses and Ergativity in German', in Jaspers, Klooster, Putseys and Seuren (1989), pp. 77-96.

Cinque, Guglielmo: 1990 , Types of $\bar{A}$-Dependencies, MIT Press, Cambridge, Massachusetts.

Culicover, Peter and Michael Rochemont: 1990, 'Extraposition and the Complement Principle', Linguistic Inquiry 21, 23-47.

Dasgupta, Probal: 1980, Questions and Relative and Complement Clauses in a Bangla Grammar, Doctoral dissertation, New York University.

Dasgupta, Probal: 1984, 'Bangla Emphasizers and Anchors', Indian Linguistics 45, 102 117.

Dasgupta, Probal: 1987, 'Sentence Particles in Bangla', in E. Bashir, M. Deshpande and P. Hook (eds.), Selected Papers from SALA 7, Indiana University Linguistics Club, Bloomington, Indiana, pp. 49-75.

Dasgupta, Probal: 1993, 'Remarks on Subjunctivity', Ms. University of Hyderabad.

Davison, Alice: 1988, 'Operator Binding, Gaps, and Pronouns', Linguistics 26, 181-214.

Engdahl, Elisabet, Mike Reape, Martin Mellor and Richard Cooper: 1990 Parametric Variation in Germanic and Romance: Proceedings from a DYANA Workshop. Edinburgh Working Papers in Cognitive Science 6.

Evers, Arnold: 1990, 'The Infinitival Prefix "zu" as INFL', in Grewendorf and Sternefeld (1990), pp. 217-238.

Fanselow, Gisbert: 1987, Konfigurationalität, Narr, Tübingen.

Fanselow, Gisbert: 1990, 'Constraints on Movement at S-Structure', in Engdahl, Reape, Mellor and Cooper (1990), pp. 109-132.

Fanselow, Gisbert: 1993, 'Die Rückkehr der Basisgenerierer', Groninger Arbeiten zur Germanistischen Linguistik 36, 1-74.

Frampton, John: 1990, 'Parasitic Gaps and the Theory of Wh-Chains', Linguistic Inquiry 21, 49-77.

Greenberg, Joseph: 1963, 'Some Universals of Grammar, with Particular Reference to the Order of Meaningful Elements', in J. Greenberg (ed.), Universals of Language, MIT Press, Cambridge, Massachusetts, pp. 73-113.

Grewendorf, Günther and Wolfgang Stemefeld: 1990, Scrambling and Barriers, Benjamins, Amsterdam.

Haan, Germen J. de: 1979, Conditions on Rules: The Proper Balance Between Syntax and Semantics, Foris, Dordrecht. 
Haider, Hubert: 1990, 'Topicalization and Other Puzzles of German Syntax', in Grewendorf and Sternefeld (1990), pp. 93-112.

Haider, Hubert: 1992, 'Branching and Discharge', Arbeitspapiere des Sonderforschungsbereichs 340 23, Universität Stuttgart.

Haider, Hubert: 1993a, Deutsche Syntax-Generativ: Vorstudien zur Theorie einer Projektiven Grammatik, Narr, Tübingen.

Haider, Hubert: 1993b, 'Detached clauses - the later the deeper', Ms. Universität Stuttgart.

Hasegawa, Nobuko: 1990, 'Comments on Mazuka and Lust's Paper', in L. Frazier and J. de Villiers (eds.), Language Processing and Language Acquisition, Kluwer, Dordrecht, pp. 207-223.

Hoekstra, Teun: 1984, Transitivity: Grammatical Relations in Government-Binding Theory, Foris, Dordrecht.

Hoekstra, Teun: 1987, 'Extrapositie en SOV', Tabu 17, 133-142.

Huang, C.-T. James: 1982, Logical Relations in Chinese and the Theory of Grammar, Doctoral dissertation, MIT, Cambridge, Massachusetts.

Jaspers, Dany, Wim Klooster, Yvan Putseys and Pieter Seuren: 1989, Sentential Complementation and the Lexicon. Studies in Honour of Wim de Geest, Foris, Dordrecht.

Kayne, Richard: 1982, 'Predicates and Arguments, Verbs and Nouns', GLOW Newsletter 8, 24.

Kayne, Richard: 1983, 'Connectedness', Linguistic Inquiry 14, 223-249.

Kimball, John: 1973, 'Seven Principles of Surface Structure Parsing in Natural Language', Cognition 2, 15-47.

Koopman, Hilda: 1984, The Syntax of Verbs: From Verb Movement Rules in the Kru Languages to Universal Grammar, Foris, Dordrecht.

Koot, Hans van de: 1988, 'The Vacuous Movement Hypothesis, Superiority and the ECP', in G. de Haan and W. Zonneveld (eds.), Formal Parameters of Generative Grammar, Foris, Dordrecht, pp. 41-51.

Koperberg, Anja: 1987, Small Clauses and Big Clauses Compared, Masters thesis, University of Amsterdam.

Komfilt, Jaklin: 1984, Case Marking, Agreement, and Empty Categories in Turkish, Doctoral dissertation, Harvard University, Cambridge, Massachusetts.

Kornfilt, Jaklin: 1990, 'Comments on the Paper by Reuland', Yearbook of Morphology 3, 163-171.

Koster, Jan: 1975, 'Dutch as an SOV-Language', Linguistic Analysis 1, 111-136.

Koster, Jan: 1978, Locality Principles in Syntax, Foris, Dordrecht.

Koster, Jan: 1987, Domains and Dynasties: The Radical Autonomy of Syntax, Foris, Dordrecht. Kural, Murat: 1992, 'V-to(-I-to)-C in Turkish', Ms. UCLA, Los Angeles.

Lasnik, Howard and Mamoru Saito: 1984, 'On the Nature of Proper Government', Linguistic Inquiry 15, 235-289.

Mahajan, Anoop: 1990, The A/A-bar Distinction and Movement Theory, Doctoral dissertation, MIT, Cambridge, Massachusetts.

Mallinson, Graham and Barry J. Blake: 1981, Language Typology: Cross-Linguistic Studies in Syntax, North Holland Publishing Company, Amsterdam.

Miller, George A. and Noam Chomsky: 1963, 'Finitary Models of Language Users', in R. Luce, R. Bush and E. Galanter (eds.), Handbook of Mathematical Psychology, vol. 2, Wiley, New York, pp. 419-489.

Müller, Gereon: 1993, On Deriving Movement Type Asymmetries, Doctoral dissertation, Universität Tübingen.

Müller, Gereon and Wolfgang Sternefeld: 1993, 'Improper Movement and Unambiguous Binding', Linguistic Inquiry 24, 461-507.

Reuland, Erik: 1991, 'Infintiven in het Fries en de Aard van Functionele Categorieen', Ms. Rijksuniversiteit Groningen. 
Riemsdijk, Henk van: 1992, 'Complements, Adjuncts and Adjacency in Phrase Structure', in L. Tasmowski and A. Zribi-Hertz (eds.), De la Musique à la Linguistique: Hommages à Nicolas Ruwet, Communication and Cognition, Ghent, pp. 498-512.

Rizzi, Luigi: 1990, Relativized Minimality, MIT Press, Cambridge, Massachusetts.

Ross, John Robert: 1967, Constraints on Variables in Syntax, Doctoral dissertation, MIT, Cambridge, Massachusetts.

Safir, Kenneth: 1982, 'Inflection Government and Inversion', The Linguistic Review 1, 417-467.

Singh, Uday N.: 1980, 'Bole: An Unresolved Problem in Bengali Syntax', Indian Linguistics 41, 188-195.

Sinha, Sunil Kumar: 1990, 'Raising in Hindi', CIEFL Working Papers in Linguistics 6.1, 78-122.

Sportiche, Dominique: 1988, 'A Theory of Floating Quantifiers and Its Corollaries for Constituent Structure', Linguistic Inquiry 19, 425-449.

Srivastav, Veneeta: 1991a, WH Dependencies in Hindi and the Theory of Grammar, Doctoral dissertation, Cornell University, Ithaca, NY.

Srivastav, Veneeta: 1991b, 'Subjacency Effects at LF: The Case of Hindi WH', Linguistic Inquiry 22, 762-769.

Stechow, Arnim von and Wolfgang Sternefeld: 1988, Bausteine Grammatischen Wissens, Westdeutscher Verlag, Opladen.

Sternefeld, Wolfgang: 1991, Syntaktische Grenzen, Westdeutscher Verlag, Opladen.

Stowell, Timothy: 1981, Origins of Phrase Structure, Doctoral dissertation, MIT, Cambridge, Massachusetts.

Stowell, Timothy: 1983, 'Subjects Across Categories', The Linguistic Review 2, 285-312.

Underhill, Robert: 1976, Turkish Grammar, MIT-Press, Cambridge, Massachusetts.

Veld, Joop: 1993, Postverbal Constituent in Dutch and Turkish, Doctoral dissertation, Universiteit van Amsterdam (Amsterdam Studies in Generative Grammar 6).

Wali, Kashi: 1988, 'A Note on WH Questions in Marathi and Kashmiri', Cornell Working Papers in Linguistics 8, 161-180.

Webelhuth, Gert: 1989, Syntactic Saturation Phenomena and the Modern Germanic Languages, Doctoral dissertation, Univertsity of Massachusetts, Amherst.

Wilder, Chris: 1988, 'On the German.Infinitival Marker $z u$ and the Analysis of Raising Constructions', Lingua 76, 115-175. 